\title{
Viajes por el Pacífico y viaje interior en el siglo
} XIX*

Qué puede ser más diferente a priori que El matrimonio de Loti, publicado en 1880, y Typee que dio a conocer a Hermann Melville a partir de 1846? Los únicos elementos de semejanza entre ambos autores son, sin duda, su pertenencia a la comunidad de marinos, tema de las dos obras: la Polinesia que se convertirá en la Polinesia francesa, así como su juventud cuando la descubrieron.

De todas formas, las mismas semejanzas son muy relativas: uno es oficial de la marina nacional, con sus tradiciones y la conciencia de su misión; el otro se ha embarcado en un ballenero, una embarcación que no se preocupa demasiado de las leyes marítimas. Uno desembarca en Papeete, donde la influencia de Occidente es ya irreversible; mientras que el otro vive en una de las tribus más salvajes de las Marquesas para escapar de la vida a bordo. Uno es producto de una sociedad en la que los hombres de letras se complacen con llamarse decadentes, escritores a la búsqueda de sensaciones nuevas y complejas; el otro, tiene la conciencia de participar en el nacimiento de una literatura nacional y, por tanto, de actualizar y forjar los valores de una nueva sociedad, casi una nueva humanidad.

¿Qué podría aproximar el universo impresionista de Pierre Loti en el Matrimonio a las descripciones en las que la virtud reside en principio mucho más en la musicalidad de la lengua que en la precisión, con su intriga convencional, demasiado remilgada para tener algún parecido con la verdad, del relato de aventuras a duras penas novelado por

\footnotetext{
Traducción del francés de Fernando Rodríguez Mansilla.
} 
Melville? En defensa de Pierre Loti, diremos que su objetivo no es el examen objetivo, sino justamente la pintura de una atmósfera indefinible y extraña, que un estudio preciso no podría ofrecer. «Nos cansamos de buscar, de coger, de explicar [...] fuerza inútil. Si algo se escapa y queda sin comprenderse [...] // He escrito sobre Tahití muchas páginas; hay allí detalles hasta sobre las más pequeñas plantas, hasta sobre la fisonomía del musgo. // Ya que se lee todo ello con la mejor voluntad del mundo. Eh, bueno, entonces, ¿̇e entiende? Seguramente que no [...]» (Loti 1991: 88).

De cualquier modo, se ha acusado a Pierre Loti —en especial lo ha hecho Víctor Segalen — de haber confundido la pintura de su corazón con la pintura de las realidades que tenía frente a sus ojos. El egocentrismo decadente, melancólico y refinado hace aparecer —en contraste- la escritura y el relato de Melville casi «neutros», fotografías que señalan, por su técnica precisa, no tanto la ausencia de juicio racional o de interpretación filosófica (se ha destacado las posturas a lo Rousseau de Melville), sino la discreción de las notas afectivas, person ales y originales.

Por su diferencia, estas dos obras pueden dar la ocasión de formular, con mayor rigor, cuestiones fundamentales sobre la naturaleza del relato exótico. ¿Y si el viaje ha sido ante todo una búsqueda espiritual, un viaje interior? ¿Hacia cuál de estos objetivos orienta la especificidad de los lugares encontrados? Estas obras ponen a prueba entonces mi intento de hacer evidentes los motivos invariables de un género literario polinesio en el siglo XIX. En efecto, estos libros podrían, a priori, esquematizar de forma muy general los dos polos extremos de la obra exótica: la búsqueda de sí mismo o más exactamente — para Loti- el goce de sí mismo; la búsqueda del «otro», en el caso de Melville. Pero ¿no sería preferible considerar toda experiencia humana como un campo de fuerzas creado por la tensión de dos polos, más que como una oposición irreductible?

Estableceremos la siguiente hipótesis: el exilio exótico, sea cual sea el deseo afirmado "de encontrar "lo nuevo" " como reza la célebre fórmula de Baudelaire, y lo que suponga el éxito o el fracaso de esta empresa, provocaba inevitablemente, sin que la voluntad del viajero sea por nada la apertura incontrolable del abismo interior, una inmersión necesaria, fatal, previa a toda renovación, una búsqueda en la que el elemento consciente podía estar casi ausente, un viaje en el que la escritura debía conservar las huellas bajo las cuales el camino pudiera ser reconocido. El psicoanálisis, como una de las claves para la crítica literaria, puede aclarar de forma útil este formidable trabajo de si mismo antes que sobre sí mismo, que es una de las dimensiones esenciales del viaje.

\section{GUADERNOS LITERARIOS}


Distingamos para empezar el viaje propiamente dicho de su objetivo o de su fin. Más que cualquier otra forma de viaje, la navegación marina es vivida por Loti y Melville como una exacerbación de la sumisión a la ley, la experiencia de una comunidad confinada dentro de límites estrictos, bajo el mando de una sola persona. Si Loti parece saborear las condiciones ascéticas, si parece encontrar una restricción más bien benéfica, que sabe se encuentra estrictamente limitada en el tiempo y que ejerce una parte del poder, Melville, por su parte, la enfrenta con impaciencia y denuncia violentamente los excesos tanto como las arbitrariedades. Pierre Loti juega a asumir la función patriarcal, Melville no cesa de huir de ella. Sin embargo, para los dos, el oasis terrestre es un alivio, una manera de olvidarse de la ley, de hecho mucho más facilmente, pues la ley en vigor es diferente, a tal punto que ellos pueden momentáneamente confundirse sobre su ausencia, y encuentran material para alimentar su rechazo y su rebeldía. El oasis aligera el peso del «súper yo», y otorga una embriagadora sensación de desorientación y al mismo tiempo puede, en una situación objetiva de dominación occidental, dar una sensación de impunidad. Desorientación que puede ser una aspiración hacia el fantasma y la proyección, que puede hacer surgir las restricciones más arcaicas de la psique; pero también llama a luchar contra los fantasmas, a reinventarse en la reconsideración de los hechos y en el enfrentamiento de las fuerzas oscuras: así Typee y el Matrimonio de Loti desarrollan apropiadamente el tema del segundo bautismo. La regresión arcaica es la condición previa del nuevo nacimiento. Vistos de esa manera, los hechos narrados en Typee no podrían ser un simple "fuera de lugar», sino que se convierten en elemento fundador. El relato de la aventura Polinesia es la fuente de Mardi y de Moby Dick y puede sin duda revelar las bases de la visión melviliana. De igual forma, el Matrimonio de Loti, segundo libro del escritor, publicado después de Aziyadé, establece con carácter duradero el canon exótico de Loti: amores desdichados e intensos con jovencitas infantiles que no podemos comprender. Estamos comprometidos a recuperar las huellas de esta regresión psíquica reveladora en Loti y en Melville. Es evidente que la marca es sencilla de ubicar en el primero; pero si la hipótesis de partida es correcta, estas imágenes raras, metáforas o las elecciones de la pluma del segundo deben estar llenas de enseñanzas.

Antes de abordar las dos obras en detalle, vamos a retomar aquí algunos presupuestos de la temática de la isla, de manera más específica de la isla Polinesia, para resaltar cómo favorece la reactivación de las estructuras psíquicas arcaicas. A menudo se ha insistido acerca del lazo casi obligatorio que une a la isla con la utopía: de la misteriosa Taprobane a la isla industriosa de Robinson Crusoe. La isla es, efectivamente, a priori un lugar aparte por 
excelencia. Cercada y protegida por el inmenso océano, sin contacto con nuestra propia realidad, es un nuevo mundo, donde todo puede ser reinventado. Su aislamiento, en el momento en que se requieren teorías evolucionistas, la ha hecho un lugar original o lo más parecido a la sociedad primitiva y, como tal, punto de partida para las reflexiones sobre los fundamentos de la sociedad humana. Este aspecto de la temática de la isla basta para explicar la dimensión fantasmal, sin necesariamente recurrir a la imagen fetal y reveladora: la isla es un lugar primordial, nacida del líquido vital. De hecho, conviene tener en mente que el hombre alimenta sus reflexiones en torno a las proposiciones de su imaginación, y, evidentemente, ésta adquiere su materia más desatendida en las fuentes más arcaicas del mundo de la psique. En estas condiciones, ¿`cómo asombrarse de que frente a la isla resurjan las pulsiones primarias, así como las primeras determinaciones construidas a partir de la pareja inicial? Pero la isla edénica tiene un reverso, el rostro sombrío del paraíso, del que se habla curiosamente poco, y es la muerte: el aislamiento es una prisión, prisión del olvido y de lo atemporal, muerte del mundo.

La isla de la Polinesia ofrece una suerte de imagen superlativa de la isla original. El lugar del cuerpo y la concepción de las relaciones sexuales son tales que el estremecimiento psíquico vencido por lo occidental es inmenso, en la medida del movimiento inverso que provocó la evangelización de las poblaciones polinesias, si bien denunciadas en las Desmemorias de Victor Segalen. El principio del placer recupera en Polinesia satisfacciones inmediatas reprimidas luego del paraíso perdido de la infancia: sensación de desnudez, la alimentación sana, goce del agua y de la vegetación, delicias olfativas y visuales, facilidad inocente del placer amoroso. Por otro lado, los viajeros se maravillan del hecho de que la vieja maldición de la Biblia, que condena al hombre al trabajo cuando se le expulsa del paraíso, no tiene aquí visos de realidad. Todo está, por ende, reunido para que la isla de la Polinesia sea la ocasión — no únicamente como podríamos creer — de abandonarse a sí misma, sino de la oportunidad de revivir las angustiantes introspecciones de las que está alejada, con más o menos fortuna, la personalidad actual. Percibida como el lugar anterior a la vida conciente, anterior a la ley y al pecado, la isla ya no se encuentra para el occidental en la otra orilla, aquélla donde la visión nos lleva más allá de la ley, sino que recuerda que la ley está para situar esa orilla de la vida definitivamente indemne. Solos, quizás, los salvajes taipis viven en un paraíso que la ignorancia de la culpa les hace desconocer.

Para emprender el estudio más detallado de estas obras, provoca, como he dicho, evidenciar el afloramiento de aquella aventura interior que escapa largamente a la experiencia 
conciente, pero a partir de la cual se puede establecer un postulado de toda aventura exótica. Podría utilizar una frase del epílogo de Gilles Deleuze a la edición francesa de Bartleby: «Todo el siglo xix será atravesado por esa búsqueda del nombre sin nombre, regicida y parricida, Ulises de los tiempos modernos ("soy nadie"): el hombre abrumado y mecanizado de las grandes metrópolis, pero del cual podemos esperar que surja el Hombre del porvenir o un nuevo mundo" (Deleuze apud Melville 1993: 180). El desvanecimiento del padre, que la experiencia individual dota de una carga fantasmal intensa, se lee, de esa forma, en torno a la sociedad en su conjunto: la ejecución del rey por los franceses, la declaración de la independencia hecha por los estadounidenses, son los hechos que los dejan huérfanos y le dan campo libre a su imaginación. Sin duda, habría que recordar brevemente que el padre de Melville tenía grandes dificultades financieras antes de morir (en ese tiempo Melville tenía trece años), y que el padre de Pierre Loti estaba en una condición social inferior a la de su madre y que uno de sus recuerdos de infancia más penosos fue la visita que hizo a su padre en prisión, luego de que fuera acusado de estafa. El clima social y el clima familiar se unen para debilitar la imagen paterna. ¿Sorprende así que las islas paradisiacas, por las razones ya mencionadas, tengan tan poco espacio para la autoridad masculina? En el Matrimonio de Loti los tahitianos están en poco número. El marido de la reina Pomaré no es sino un bello especimen reproductor que ha destacado en su función y no desempeña más que ese papel en la corte. El padre de Rarahu muere sin que ella se digne a llorarle: «Este anciano frío no hace mucho más que dejarla crecer [...]; su cuerpo espantoso que estaba allí no le inspiraba más que un inmenso horror» (Loti 1991: 115). Tamatoa, otra figura viril relativamente desarrollada en el relato, es el hijo de la reina Pomaré y el padre de la joven y patética princesa heredera que murió de tisis, con desesperación de su abuela. Tamatoa es confinado en el palacio materno, ya que es víctima de una crisis de locura sanguinaria; Loti pasará junto a él una noche llena de angustias. Un día el príncipe se escapará para cometer una serie de horribles asesinatos, por los cuales Loti parece tener una especie de fascinación. Lejos del universo femenino, los tahitianos representan una amenaza imprevisible, una intrusión brutal y sin perspectiva.

En los taipis vistos por Melville, la figura paterna es también muy despreciada. Marheyo, con quien Tommo (Tom) está alojado, no es sino un viejo decrépito y senil, de actividades tan diversas que están aparentemente desprovistas de utilidad. A pesar de ser un médico que fue próspero, Marheyo es inofensivo. Es por cierto gracias a su bondad y a su debilidad en el cerebro que Tom podrá finalmente irse del valle. En el Ti, la casa comunal de 
los hombres, viven permanentemente un grupo de ancianos, cuya actividad se reduce a que se crea que están ya muertos. Su retrato trae un asco casi odioso: «Su piel tenía un horrible aspecto de escamas [...], su cuero colgaba en alguna s partes en grandes pliegues [...]. Esos seres repugnantes parecían enteramente privados del uso de sus miembros inferiores. Ellos no pusieron la más mínima atención en nosotros [...], sumidos en un vago estupor» (Melville 1984: 137). Mehevi, el protector amigo de Tommo no se revelará como marido, padre y rey, sino muy tardíamente en el relato (cáps. XXV y XXvi) y aun así sus funciones son muy matizadas por el narrador. Mehevi no recibe ningún tratamiento especial de respeto, tampoco escapa de la costumbre taipi de la poliandría, que vuelve la filiación paterna muy misteriosa: «Sin embargo, Mehevi no era el único a la que la señorita Moonooni reservaba su sonrisas; el joven de quince años, que vivía permanentemente en la misma casa que ella, estaba sin duda dentro de sus favoritos. Yo vi algunas veces al jefe y a él poniéndose de acuerdo» (Melville 1984: 265). Cabe señalar que sus revelaciones sobre el rey están precedidas de un curioso capítulo, al final del cual Kory Kory, el sirviente de Tom, se ensańa con un Tiki, bajo la mirada horripilada del último, que ve en ello una profanación y concluye en una decadencia moral y religiosa de los taipis. Las figuras paternas de poder, cualquiera sea su forma, son entonces demolidas o transformadas para ser más aceptables.

Paralelamente a este debilitamiento, contemplamos — de forma muy evidente- en Pierre Loti, más fantasmal en Melville, una invasión del campo de la psique por una imagen materna en la cual el poder fascina y asusta. El poder social es, en el Matrimonio de Loti, un poder femenino. Pomaré, como la «cabeza imperiosa y dura», se rodea de una pompa real y se nos presenta siempre como una guardiana fiel a las tradiciones, como la pastora inquieta de un ganado amenazado por la presencia europea. En torno a ella se organiza la vida de la capital y es ella también quien decidirá el casamiento polinesio de Loti y Rarahu. En las Islas Marquesas, reina también una mujer que lucha contra los mismos problemas que Pomaré. La imagen más obsesiva y sin duda más fuerte en el Matrimonio de Loti es definitivamente la de las mujeres reunidas e inmóviles que parecen guardar un secreto en torno al cual el héroe indaga en vano. En la narración se pasa de la evocación del «encanto indefinible» (Loti 1991: 55), del cortejo de mujeres de Pomaré en la penumbra de una tarde tropical, a la del de las mujeres de la reina Vaékéhu que «te miran venir con una expresión de salvaje ironía» (Loti 1991: 109).

De regreso de California, Loti es víctima de una impresión penosa que se concreta con el encuentro nocturno con las hijas de la reina: «Una tristeza inquieta, sin causa conocida, me 
penetra poco a poco en medio de este silencio inesperado; se diría que este país está muerto» (Loti 1991: 176). Finalmente, la narración se cierra con una "confusa visión de la noche». Natuaea magnífica baja a los infiernos, a la luz de «un gran sol muerto» en el que el círculo de madres muertas vela el joven fantasma de Rarahu: «Ella parecen estar allá luego desde hace un tiempo indefinido [...] sus largas cabelleras las cubren casi por entero, ellas estaban inmóviles; sus ojos estaban cerrados, pero, a través de sus párpados transparentes, distinguía sus pupilas fijas en mí [...]» (Loti 1991: 229). Personificaciones del remordimiento, ellas parecen velar por aquél que las ha abandonado, pero que volverá algún día. Diosa tutelar, Pomaré gobierna un reino en el que tiempo ha sido abolido, un reino en el que persiste la inocencia. Cada vez que el héroe tiene la conciencia del hecho que se fija en el infinito del goce, se trata de un morir para el mundo o, de cierta manera, morir para sí: él escogerá entonces huir después de haber saboreado plenamente el espejismo paradisíaco: «Yo soñaba que podía tener un encanto soberano para ir a vivir con ella como con una pequeña esposa, en un distrito medio perdido, en una de las islas más lejanas y más ignoradas de los dominios de Pomaré — para ser olvidado de todos y muerto para el mundo—; para conservar allá a la que amo (Rarahu), singular y salvaje, con todo lo que hay en ella de frescura e ignorancia» (Loti 1991: 125). ¿No es toda la vida de Loti, ese incesante ir y venir entre diversas estancias, donde él da vida a sus fantasmas y a sus sueños, y la dura disciplina a bordo cuando él viste un uniforme paterno prestado, un ir y venir en el que el yo a la vez se pierde y se reconoce en sus múltiples facetas? La escala polinésica está en el origen de esta concepción de la existencia que será siempre una parte importante para la recreación de los espejismos de la infancia; ella está también en el origen del descubrimiento de esa sabiduría sin memoria que asimila la atracción por el universo materno a la atracción por la muerte. En efecto, tanto como el amor, la muerte es el tema mayor y obsesivo del Matrimonio de Loti: muerte de Rarahu y de numerosos personajes, defunción de la cultura y de la raza polinesia, apariencia sin vida de los cuerpos adormecidos, presencia obsesiva de los cementerios maoríes, precariedad de la vida humana frente a la perennidad geológica de las islas.

En Typee, de Hermann Melville, la figura materna no aparece muy directamente o bien es insignificante, como Tinoa, la mujer de Merheyo, en la cual la actividad incesante de hormiga acaba por dar una impresión de vanidad y vacuidad. Se hace notar la interesante evocación de la reina de las Islas Sandwich, la «monstruosa Jézabel» que no soporta ningún atentado contra su poder: «La vieja reina madre gigante, Kaahumanu [...] había acostumbrado, durante algunos de sus terribles accesos de cólera, coger a un hombre de talla normal que 
la había ofendido y romperle la columna vertebral sobre sus rodillas» (Melville 1984: 260). ¡Esta imagen está tan lejos de los tópicos habituales! El tema maternal resurge de manera bien evidente con la preocupación constante por la alimentación, la obsesión caníbal.

Así, es la madre misma, al inicio del texto, la naturaleza insular entera, que pese a su obstinado vigor no consiente garantizar la subsistencia de los dos marinos. Ellos sufren todas las ansias del hambre, pero serán vistos por los autóctonos como unos «caníbales blancos» (Melville 1984: 103), lo cual resalta el rendimiento de este tema con la relación alimentaria de la madre y del niño, el estadío oral del momento en que salen los dientes, como lo definía Freud. El miedo a ser devorado, vinculado a las contracciones debidas al hambre y al sueño es suscitado por el fantasma de una madre terrible que quiere comerse a su hijo, el cual siente paralelamente el deseo de devorar el seno materno. Recordemos también a este propósito la escena altamente simbólica de la representación del lechón asado que provoca una profunda repulsión en el personaje: «¡Es un niño asado, por el alma del capitán Cook! [...] Con estas palabras, tuve la brusca impresión de haberme tragado toda una dosis de emético y agua tibia [...]. Pero decidí tener el corazón limpio, con todo lo que me tuviera que costar» (Melville 1984: 139).

El canibalismo real de los taipis parece tener el poder de expulsar la psique del personaje principal hacia las zonas oscuras de una historia arcaica. Esto explica, sin duda, las diferencias de apreciación que se pueden hallar en la obra, de la explicación más razonablemente etnológica (cf. Melville 1984: 286) a la fobia más visceral que en el imaginario europeo vincula la ausencia de tabú caníbal con la ausencia de ley moral, la animalidad y la satisfacción de los instintos más bajos y más inmediatos (ibíd.). Sea lo que sea — para Melville, como para Loti- el poder tutelar femenino es siempre mortífero, amenaza de fusión y, por tanto, de desaparición en tanto inviduo socialmente distinto. Un último episodio puede convencernos de ello en Typee. Convencido de su superioridad viril, Tommo quiere jugar a asustar a una joven mujer sumergiéndola hasta el fondo del agua, pero no se da cuenta de que es él quien se pone en riesgo de ahogarse hasta el punto que dice: «Los ruidos insólitos que me zumbaban en las orejas y las visiones sobrenaturales que bailaban frente a mis ojos me hicieron saber que había llegado al mundo de los espíritus» (Melville 1984: 186).

La infantilización del héroe del Matrimonio y de Typee es también muy evidente, esencialmente en Melville, donde el héroe es reducido a una dependencia extrema. Los actos vitales de la existencia no pueden llevarse a cabo sin la ayuda de otra persona, como Kory Kory, que le hace comer de su propia mano, que lo lava con dulce cuidado sin importarle 
su pudor, o que lo lleva sobre las espaldas con una constancia loable. Pero la inmadurez es, sin duda, incluso más evidente respecto a la relación amorosa. Sea porque la naturaleza de las relaciones entre Faiaohae y Tommo o aun Loti y Rarahu son inequívocas, la pintura de ellas se hace extremamente vaga y discreta. En el caso del Matrimonio de Loti vemos una evolución de la sexualidad que va de una pura relación fraternal al inicio del texto hasta al desborde desesperado de los dos personajes al final del relato. Pierre Loti insiste complacido en la juventud de sus dos personajes y sobre la bendición paternal que reciben sus amores casi incestuosos. Estamos en un paraíso, indudablemente, más allá del bien y del mal: «Nos dormimos uno junto al otro, un poco como si fuéramos dos hermanos [...] Los viejos padres de Rarahu [...] habían juzgado que Loti valía más que cualquier otro, Loti tan joven como ella, que le parecía dulce y que parecía amar» (Loti 1991: 63). En cuanto a Tommo, él usa con humor el vocabulario más inadaptado, anacrónico incluso para un europeo, ya que él quiere describir la naturaleza de sus relaciones con Faiaoahé, que él califica encantado como ninfa o jovencita: «Si mi lector no ha notado todavía que yo era admirador declarado de la señorita Faiaoahé, todo lo que puedo decir es que sabe poco sobre asuntos del corazón» (Melville 1984: 190), Faiaoahé podría aparecer como una suerte de compañía fraterna, difícil de diferenciar, bajo cierta mirada de Kory Kory.

Es innegable que, más allá de la diferencia de su escritura y de su personalidad, Pierre Loti como Herman Melville se hallan confrontados en la isla Polinesia a un momento capital y arcaico de su historia psíquica, el momento en el que el individuo se define en relación con la entidad materna, a la vez fascinante, atractiva y peligrosa, y aquél en el que la entidad paterna es debilitada por razones tanto personales como sociológicas. Sin embargo, de cara a la diosa madre, su actitud será diferente. Para Pierre Loti, la isla materna es, sin ambages, acogedora: él insiste bastante sobre la benignidad de las especies animales y vegetales, la seguridad de las personas, y el sentido de la hospitalidad de los polinesios. Si la isla madre es peligrosa, lo es en la medida en que ella atrae una felicidad fuera del tiempo y de las restricciones inmediatas de la civilización. No obstante, la atracción a la que cede con voluptuosidad el personaje durante la estancia, se colma de un conocimiento frente al cual no se puede escapar: la necesidad de una identificación del padre como camino de individualización. Fijémonos de paso en el tema menor del canibalismo, que acompaña incidentalmente todo el relato, con un episodio en apariencia incongruente, pero simbólicamente importante en el cual vemos a la reina caníbal que se retira a un rincón para restituir lo que ha ingerido, lo cual permite de alguna manera, siempre en modo figurado, la existencia viril. 
Por otra parte, el Matrimonio de Loti duplica la temática del Edén mediante la búsqueda de una imagen paternal satisfactoria bajo la forma de la búsqueda de los niños tahitianos del hermano mayor muerto, al que quiere sustituirse. Esta búsqueda de sí a través de otro es de una gran complejidad fantasmal que otorga una dimensión misteriosa y extraordinaria a ciertas páginas. Loti experimenta la inmensa seguridad que procura un sentimento de paternidad que trasciende el tiempo y vence la muerte, pero él vuelve a ser, al mismo tiempo, el niño huérfano, angustiado y patético que sin duda fue. El intento de identificación con el hermano padre fracasará, llevando al personaje a su papel puramente social de oficial de la marina, persona jungiana, máscara mal puesta en solución de continuidad con el ánima femenina: «Una gran depresión acaba de ocurrir, un gran vacío en mi corazón — cosa extraña, estaba aferrado a la idea de esta familia tahitiana—, y este vacío que se sentía allá me causaba un dolor misterioso y profundo; era algo así como que si mi hermano hubiera estado sumergido mucho antes y por siempre en la nada y parecía que las islas se volvieran súbitamente desiertas, que todo el encanto de Oceanía hubiera muerto de golpe y que nada me atase ya a este país» (Loti 1991: 192).

En Melville, como hemos intentado demostrar, la maternidad de la isla Polinesia es mucho más simbólica que en Loti y el aspecto negativo está mucho más acentuado. Pero otras diferencias son perceptibles, de forma que podemos resumirlas, en una perspectiva bachelardiana. La isla de Loti es un universo terrestre, geológico y vegetal; en tanto la isla de Melville es una vasta tierra de naturaleza ambigua, donde el agua se sustituye insensiblemente con peñascos, piedras y suelo. Al explicar su angustia de lo que le espera a las Marquesas convertidas al cristianismo, Melville utiliza la llamativa expresión «islas de la mar» para designarlas (Melville 1984: 272). Al llegar a tierra luego de largos meses en el océano, el héroe «tenía la impresión de flotar en un elemento nuevo, en tanto que toda clase de sonoridades acuáticas, murmullos, lluvia, resonaban en mis oídos» (Melville 1984: 50).

Recordemos también la escena extraordinaria del bebe de las Islas Marquesas en el río, «que chapotea como si hubiera salido a la superficie justo después de haber tocado el fondo» (Melville 1984: 315), en el que el agua se convierte en elemento fecundador por excelencia, en detrimento de todo el proceso sexual. La gente de las Marquesas es llamada a sí misma «raza anfibia» (Melville 1984: 316) y los juegos acuáticos se vuelven un ballet de sirenas o de peces fabulosos (Melville 1984: 186). Esta ambigüedad en relación a la naturaleza del ser humano se pone de manifiesto también en lo que concierne a la diferencia sexual: los

\section{CUADERNOS UTERARIOS}


lapsus o las imágenes son demasiado numerosos para no ser reveladores. Cuando el capitán se esfuerza en disuadir a los marinos de volver a tierra, uno de ellos le apostrofa: «Siempre, mi vieja» (Melville 1984: 59).

El jefe Mehevi será siempre comparado con una «tierna madre» (Melville 1984: 118), Marnoo tiene la mejilla «lisa como la de una mujer» (Melville 1984: 192) y el narrador, por su parte, está vestido con una especie de traje femenino y se compara placenteramente con una jovencita caprichosa: «Una beldad a la moda, fiera en su perfección y su poder» (Melville 1984: 193; cf. p. 226). Faiaoahé, a la inversa, fuma y se sube a una piragua como si fuera un hombre, lo cual no hace sino acrecentar su encanto: «No hay otra circunstancia en que una mujer joven y bella aparezca más favorecida que cuando está fumando» (Melville 1984: 189). Tierra ambigua y por la misma tierra, valorado positivamente, el valle de los taipis se parece mucho a aquella sociedad fraternal que ciertos críticos han considerado el origen de la búsqueda de Melville, una sociedad que ha abolido la autoridad paterna y que puede entonces ser ansiada como una liberación por venir, pero que, puesto que ella niega la realidad de la diferencia sexual y el tabú del incesto, bordea siempre peligrosamente las zonas de la transgresión arcaica, como las que retrata el filósofo alemán Bachofen en su obra sobre el matriarcado. Gilles Deleuze evoca excelentemente esa «zona de indistinción, de no poder discernir, de ambigüedad, que se establece entre dos términos, como si afectaran el punto que precede inmediatamente a su diferenciación respectiva: no es una similitud, sino un desplazamiento, una vecindad extrema; una contigüidad absoluta; no es una filiación natural, sino una alianza contra natura. La psicosis persigue su sueño, asienta una "función de fraternidad universal" que no pasa ya por el padre, que se erige sobre las ruinas de la función paterna, supone una disolución de toda imagen del padre que sigue una línea autónoma de alianza o de vecindad que hace de la mujer una hermana, otro hombre, un hermano» (apud Melville 1993: 185).

A manera de comparación, en la obra de Pierre Benoît, al inicio del siglo xx, durante el periodo de entreguerras, la creación imaginaria oscila entre dos polos antitéticos: el Edén maternal y la adhesión realista. Esta duda obedece de hecho tanto a la época como a la personalidad misma del escritor (hijo de un oficial del ejército colonial, que había pasado su infancia en Túnez y luego en Argelia). Recordemos que, publicada en 1919, La Atlántida, descripción de un extraordinario oasis en el desierto es, en la obra, la imagen más nítida de un paraíso perdido que aparece en la mayoría de las novelas del autor. Sociedad de la satisfacción de todos los placeres, donde todo está orientado hacia la voluptuosidad. La Atlántida tiene por soberana una mujer fatal, en el sentido de que ella mata a todos sus amantes. Este paraíso 
donde el amor y el placer son sinónimos de muerte en el mundo revela más claramente su origen, que es la nostalgia de una relación que implica una fusión con la madre que es sumamente mortífera, por tanto, peligrosa.

En Erromango, publicada en 1929, la temática del paraíso perdido triunfa también en gran parte de la celebración de la aventura colonial. En efecto, el ingeniero Fabre, australiano de ascendencia francesa, ha adquirido los valores capitalistas fundamentales: el trabajo, el progreso técnico y científico, el éxito por el mérito, el cual consiste esencialmente en producir riquezas. Luego de mucho investigar, Fabre considera aclimatar una raza de corderos en las islas del Pacífico, más precisamente en Erromango, isla próxima a la actual Vanuatu. Todo ocurre según su plan, hasta que la imagen obsesiva de la mujer fatal y del amor que nunca experimentó aparece, poco a poco, a minar la empresa y reducirla a la nada. La obsesión de la joven hace tiempo conocida en Sidney se refleja en la imagen fantasmal del poder aplastante de una naturaleza tropical tanto como en la evocación fascinada de los pueblos autóctonos que se entregan libremente al canibalismo durante ceremonias seductoras. Bajo los efectos de su imaginación, del alcohol y de la fiebre, Fabre se hunde lentamente y culmina de forma miserable su aventura con el suicidio.

Por ello, entre burlas y desesperación, los personajes de Pierre Benoît quedan como bien pensantes y la lección es a fin de cuentas extremadamente conservadora. Sin duda, esta es una de las razones que hace que el éxito que tuvo este escritor nos parezca un poco incomprensible. En efecto, en Erromango, la última palabra es para Jeffries, colono ejemplar, encargado de transmitir el mensaje siguiente: aquél que sigue el camino de los virtuosos capitalistas occidentales sin dejarse distraer será recompensado. Sobrio, trabajador y defensor de su feudo sin bajar nunca los brazos, Jeffries no resulta simpático. Por tanto, él intentará muchas veces advertir a Fabre y ayudarlo, él lo lleva a su estancia durante una noche en la que Fabre ha bebido mucho, le da un medicamento contra la fiebre, le entrega una oveja perdida, le advierte sobre el accionar de Bliss y Cross. No llegará a cambiar su destino. Es cierto que la suerte de los otros no le preocupa demasiado, ya que está persuadido de que el éxito no puede ser sino individual: «Hay que ser precavido. ¡Qué hay quien quiere aprovecharse de mí! Un lugar en el que hace diez años no se cargaban diez sacos. Ése no es un holgazán, sabes» (Benoît 1996: 325). El lenguaje trillado del capitán de la goleta simboliza muy bien hasta qué punto el éxito de Jeffries está falto de poder de preparación y de proyección: esta lección de vida se parece demasiado a la realidad para suscitar el entusiasmo o el ensueño. 
En Polinesia, Melville y Loti — por un proceso fatal— han sido presos de quimeras infantiles y los dos han extraído sin duda una buena parte de su visión original del mundo, ya que ambos han mantenido, de cara a las más deliciosas tentaciones, la conciencia del pecado y de la necesidad de la ley, que ha alimentado su voluntad intacta de «re-partir» para convertirse en ellos mismos. Lo han hecho, con la sensación de cometer un crimen contra sus dobles fraternales, sus hermanos salvajes, que viven en una inocencia que no pueden compartir más, sino en breves momentos: Loti conducirá a Rarahu a la muerte, Tommo no deberá su salud sino a un golpe de remo que le propina a Mao-Mao. No obstante, el recorrido por las zonas oscuras y arcaicas del imaginario se muestra necesario para hacerse de un modus vivendi original o trazarse los contornos sońados de un porvenir para la humanidad: las islas polinesias no son un cliché y un mito, sino que ellas reactivan los principios iniciales de la eterna aventura de la conciencia humana. En Erromango, al inicio del siglo xx, entre el desastre de la primera guerra mundial y la Gran Depresión económica, la elaboración utópica ya no tiene lugar entre la resignación realista y la regresión mortal. 


\section{BIBLIOGRAFÍA}

BACHOFEN, Johan Jakob

1980 Du Règne de la Mère au patriarcat. Lausanne : Agora.

Benoît, Pierre

1994 L'Atlantide. París: P. Laffont.

1996 Erromango. París: La Table ronde.

BACHELARD, Gastón

1993 L'Eau et les rêves. París: Le Livre de poche.

Loti, Pierre

1991 Le Mariage de Loti. París: GF Flammarion.

Melville, Herman

1972 Typee. Londres : Penguin Classics.

1984 Tä̈pi. París: Folio Edición.

1993 Bartleby. París: Livre de poche. 